\title{
AURORA COLLEGIAL: UM JORNAL DOS ALUNOS DO COLÉGIO ANCHIETA
}

\author{
Ligia Bahia Mendonça* \\ lattes.cnpq.br/2704144844468237
}

\begin{abstract}
Resumo: Os periódicos escolares exerceram o papel de divulgadores e reforçadores das ideias e práticas de dadas instituições, ao mesmo tempo em que possibilita aos historiadores visitar e compreender aquela realidade. Este artigo investiga o jornal Aurora Collegial (1905-1922) produzido pelos alunos do Colégio Anchieta, à luz da História Cultural. Tomo o periódico como objeto e fonte de modo a poder historiar, através dos indícios do cotidiano escolar, valores, costumes e interesses que balizavam a educação jesuíta nos anos iniciais do século XX. Tratando o objeto/fonte na materialidade, reflito sobre as representações que difunde por práticas, formação religiosa e educação. A pesquisa pretende colaborar com os estudos sobre os periódicos escolares em instituições religiosas.
\end{abstract}

Palavras-chave: Aurora Collegial; Educação jesuítica; Periódicos escolares.

\section{AURORA COLLEGIAL: A JOURNAL OF STUDENTS OF THE ANCHIETA COLLEGE}

\begin{abstract}
School journal shave played the role of disseminators and reinforcers of ideas and practices of certain institutions, at the same time that haveen abled historians to visit and understand such reality. This article investigates the Aurora Collegial periodical (1905-1922) produced by the students of Anchieta College, in the light of Cultural History. I take the periodical as na object and source of narrating facts, through the evidence ofeveryday school life, values, customs and interests that marked Jesuit education in the early years of the twentieth century. By treating the object / source in materiality, I reflect on the representations that spread through practices, religious formation, and education. The research intends to collaborate with the studies on the school periodicals in religious institutions.
\end{abstract}

Keywords: Aurora Collegial; Jesuit education; School periodical.

\footnotetext{
* Doutoranda em Educação pela Universidade do Estado do Rio de Janeiro, UERJ (Brasil). Contato: ligiabahia@gmail.com.
} 


\section{Introdução}

Na historiografia da Educação têm sido crescentes as pesquisas cujo corpus documental é o impresso. No estudo do impresso tornou-se relevante a investigação sobre os periódicos escolares na perspectiva de Chartier (2009, p. 47), de que é necessário "pensar a articulação entre os discursos e as práticas”. Assim, dar-se a organização da apreensão do mundo social, percorrendo categorias como: representação, apropriação e prática (CHARTIER, 1990, p. 17).

Robert Darnton (1990) refletiu sobre o papel dos meios de comunicação, da leitura e do Iluminismo, dedicando-se aos leitores comuns, sobre o que liam, como liam e qual o significado desta leitura na vida destes sujeitos. Nessa perspectiva, se o jornal do colégio tinha como público alvo os alunos do educandário: que representações o jornal desejava que fossem apropriadas pelos alunos? Que práticas descritas no periódico enfatizavam tal objetivo?

Sobre a imprensa pedagógica estudos inovadores, brasileiros e de outros países, trouxeram a perspectiva das potencialidades destas fontes para história da educação, como Denice Catani e Maria Helena de C. Bastos (1997), Antonio Nóvoa (2002), Pierre Caspard (2002), Maurits De Vroede (1973/1987), Giorgio Chiosso (1997), dentre outros.

As pesquisas corroboram as modificações que a leitura e a escrita vêm sofrendo durante os séculos, do manuscrito à tecnologia digital, tomadas como práticas culturais refletem seus usos e funções, procurando a interpretação das práticas sociais de escrever e de ler (CASTILLO GÓMEZ, 2003, p. 97). O autor espanhol admite ainda que a história da cultura escrita é o resultado "una triple conjunción: historia de las normas, capacidades y usos de la escritura; historia del libro y, por extensión, de los objetos escritos (manuscritos, impresos, electrónicos o en cualquier otro e historia de las maneras y prácticas de la lectura”. A escrita deste jornal pelos alunos do Colégio Anchieta deixa de ser apenas símbolos gráficos, forma ou diagramação, e passam a representar práticas culturais. 
Assim, o estudo sobre um periódico dedica-se à materialidade do suporte. Os textos ali veiculados, sob as práticas de escrita e leitura, e outros elementos inerentes ao impresso, permitem a observação de uma realidade possível, ou seja, do cotidiano escolar.

Bastos e Catani (1997), no estudo sobre a imprensa pedagógica e a história da educação, salientam que os impressos educacionais eram escritos por professores para professores, para alunos e por alunos e seus pares. As autoras consideram que:

\begin{abstract}
A imprensa é um corpus documental de vastas dimensões, pois se constitui em um testemunho vivo dos métodos e concepções pedagógicas de uma época e da ideologia moral, política e social de um grupo profissional. É um excelente observatório, uma fotografia da ideologia que preside. Nessa perspectiva, é um guia prático do cotidiano educacional e escolar, permitindo ao pesquisador estudar o pensamento pedagógico de um determinado setor ou de um grupo social a partir da análise do discurso veiculado e da ressonância dos temas debatidos, dentro e fora do universo escolar. (CATANI; BASTOS, 1997, p. 5).
\end{abstract}

Neste filão destaca-se o impresso estudantil, que permite, por meio da perspectiva da cultura e materialidade, apreender uma experiência do cotidiano do Colégio Anchieta, proporcionando olhar espaços e saberes escolares que não são neutros e que necessitam ser compreendidos a partir do seu significado e sua representação (VIÑAO FRAGO, 1998). Essa escrita auxilia os historiadores na construção de histórias dos sujeitos, sejam professores ou alunos, suas reivindicações, os saberes em circulação, os métodos de trabalho, material didático, dentre outros temas que podem ser investigados (HERNANDEZ DÍAZ, 2013).

Em 25 de maio de 1905, os alunos da Divisão dos Maiores, do Colégio Anchieta escreveram o primeiro número do periódico quinzenal $\mathrm{Au-}$ rora Collegial. Dedicado à notícia, fez referência na maioria das vezes aos acontecimentos internos, à recreação, voltada para a descontração por meio das "risotas", e à instrução. Consagrou aos estudantes o estudo da língua pátria, tanto pela escrita, quanto pela leitura. Essa iniciativa foi elogiada por meio de cartas remetidas aos jovens jornalistas. 
O Núncio Apostólico da Santa Sé no Brasil, Giulio Tonti ${ }^{1}$, no dia 4 de junho de 1905, abençoa os rapazes:

Aos caríssimos alunos da Divisão doa maiores do Colégio Anchieta, redatores da Aurora Collegial Monsenhor Julio Tonti felicita pela ideia, por eles realizada, de um periódico quinzenal, e os abençoa de todo coração, fazendo os mais ardentes votos, o que no porém, semelhante publicação seja um novo estímulo para o jornalismo periódico, Catholico no Brasil. (Aurora Collegial, 25/5/1905, p. 17).

Mais do que elogioso, o Monsenhor parece ter tecido, ainda que tacitamente, uma crítica aos outros jornais católicos brasileiros. Outra correspondência, datada de 30 de junho de 1905, que elogiou a empreitada foi a do Conde Affonso Celso²:

[...] A par de cordialissimos agradecimento, queira a digna redação da auspiciosa folha aceitar sinceros emboras, pela elevação de intuitos de nobreza de forma todos os artigos. Oxalá apresentassem correcção egual muitos dos chamados órgãos de imprensa! De tão formosa alvorada sahirá, sem dúvida, magnífico dia, radiante e fecundo. É o que espero e desejo. Que Deus abençoe, proteja e prospere sempre os jovens e galhardos jornalistas! (Aurora Collegial, 25/5/1905, p. 17).

Além de engrandecer a correção com a qual foi escrito o jornal, comparando-o a outros periódicos, pareceu engendrar, nas páginas do impresso, proximidades com sua própria escrita em "Porque me ufano do meu país”3, dentre outras. Diante do respaldo recebido, o Aurora Colle-

\footnotetext{
${ }^{1}$ Giulio Tonti foi o primeiro Núncio da Santa Sé no Brasil, quando então, a internunciatura foi elevada à nunciatura. Na primeira, dentre outras deliberações, pelo Decreto 119-A, o internúncio não precisava aguardar a nomeação de bispos feita pelo Imperador, poderia ele mesmo, designar os nomes para o bispado. A nunciatura representou a presença papal, a intensificação da organização católica no Brasil. Cf. ROSA, 2011; AQUINO, 2012.

${ }^{2}$ Afonso Celso de Assis Figueiredo Júnior nasceu em Ouro Preto, em 1860. Dedicouse à política até 1903, quando em um protesto "silencioso" contra a República, recusa-se a voltar para Câmara. Entre outras funções foi orador, escritor, jornalista, historiador e professor. Destaca-se ainda, por ter sido um dos fundadores da Academia Brasileira de Letras. Cf. BARROS, 2002.

3 A editora Laemert fez a primeira edição em 1901, em razão da celebração do quarto centenário do descobrimento do Brasil. Foi traduzido para o francês, alemão, italiano
} 
gial seguiu um percurso por 17 anos, encerrando sua produção em 1922, já com 235 exemplares.

\section{O berço: Colégio Anchieta}

O colégio jesuíta foi aberto em 12 de abril de 1886, na cidade serrana de Nova Friburgo (Rio de Janeiro), conforme noticiado pelo $O$ Paiz e $O$ Apostolo em pequenas notas. Inicialmente funcionou numa casa alugada por 1:500 $\$$ anuais, onde foram feitos alguns reparos. Era uma sucursal do Colégio São Luis 4 , em São Paulo. José Antônio Braga Sobrinho (1955), que foi um dos primeiros alunos da instituição, narrou sua chegada:

Em 1886, no mês de abril, naquela tarde fria de céu azul sem nuvens, sentido-se já o aproximar do inverno, cinco meninos subiam a íngreme ladeira do "Château", eram eles: Emanuel Muniz - José Antonio Braga Sobrinho - Carlos Vaillant de Oliveira - Eloy de Andrade Câmara - Mario Teixeira da Costa. Estavam, quase todos na maioria acompanhado pelos seus pais.A larga e velha porta do colégio achava-se aberta de par em par e não tardou em aparecer o Reverendíssimo P. Lourenço Rossi (Reitor) para receber aquêles cinco primeiros alunos que inauguravam dest'arte o novo Colégio Anchieta. Fomos conduzidos para o interior do colégio e logo após para o recreio, onde na mais completa liberdade nos distraímos e apreciamos o belo panorama que do alto avistávamos: - a cidade lá em baixo, tão tranqüila, mergulhada num doce remanso, ouvindo-se apenas compassadas do Sino da Igreja Matriz, convidando os fiéis à oração do Ângelus. (SOBRINHO, 1955, p. 7).

José Antônio Braga Sobrinho escreveu em "Reminiscências dos primeiros tempos do Colégio Anchieta de Nova Friburgo" as lembranças vividas ao longo de mais de 50 anos. Verdade ou ficção, não importa. Vale o que é destacado na hora de narrar ou escrever, pois seu relato se

e inglês, com a intenção de demonstrar a superioridade brasileira. Cf. BARROS, 2002.

4 O Colégio foi fundado pelos jesuítas, em 1867, na cidade de Itu, até que em 1917 partiu para seu novo prédio na parte central da cidade de São Paulo. Cf. MENDONÇA, 2010. 
apresenta como memória do Colégio a partir da sua visão. Como ensina Benjamin (1994), o narrador retira de sua experiência, ou da de outros, aquilo que narra.

Lá do alto, os alunos observavam o notório desenvolvimento na cidade, nos setores econômico, político e cultural. Para João Raimundo Araujo, isso ocorreu principalmente a partir de 1890, período de apenas quatro anos após a fundação do Colégio Anchieta. A emancipação de Nova Friburgo em relação ao Município de Cantagalo, segundo Araujo, fez parte dos jogos de interesse propostos pela nova situação política da recém proclamada República brasileira, pois com:

A ascensão de novos grupos políticos e a necessidade dos acordos regionais, podemos perceber a criação, em toda Velha Província, de novos municípios. Tratava-se de um rearranjo político inventado por novas elites que assumem o poder com advento republicano. A transformação de Nova Friburgo em município faz parte de novo arranjo político na ex-província, agora Estado do Rio de Janeiro. (ARAUJO, 2003, p. 25).

A cidade de Friburgo assumiu um papel de receptora da população proveniente de outros municípios em busca de tranquilidade, clima saudável, bons serviços e inclusive, para a educação dos jovens (ARAUJO, 2003, p. 42).

O Colégio Anchieta recebia apenas rapazes sob o regime de internato, constituindo-se numa característica do período. Riolando Azzi (2004, p. 15) considerou que os principais motivos para a força dos internatos se dava "frente à distância e à dificuldade de comunicação entre os centros urbanos e as regiões do interior; [diante disso] julgava-se que a melhor forma de educar as crianças era mantê-las em regime de reclusão”. A disciplina rígida existente nesse modelo escolar submetia os alunos à vigilância permanente, visando o bom andamento do colégio e o cumprimento dos regulamentos. Constituía-se em características básicas dos colégios religiosos, e particularmente dos colégios jesuítas, para alcançar a desejada educação humanística e formação do aluno inaciano.

Num período que abarca o ano de sua fundação, até o momento em que perde os privilégios de Ginásio Nacional (1886-1915), o Colégio An- 
chieta teve um total de 2.315 alunos. Desses, 1.301 eram naturais do Rio de Janeiro, mas havia estudantes de pelo menos 20 estados e de diversas capitais do Brasil; e ainda 46 alunos de nove países diferentes, sendo a maioria portugueses. Foi significativo o número crescente de alunos, inclusive durante a construção do edifício definitivo do Colégio. Entre 1903 a 1908, os números foram de 255, 269, 271, 287, 398, 374, respectivamente.

\section{O jornal dos alunos: Aurora Collegial}

No colégio jesuíta foram localizados 22 exemplares do periódico, publicados entre os anos de 1905 e 1915, encadernados e listados. No Centro de Documentação D. João VI (Pró-Memória de Nova Friburgo) estão 155 exemplares, cujos anos correspondem de 1905 até 1922, que foram digitalizados pelo centro de documentação.

Os responsáveis pelo periódico eram oriundos da divisão dos maiores5. No seu primeiro número, na coluna "Nosso Programma", pode-se encontrar algumas descrições sobre o jornal. Foi lançado em maio e prometeu-se até o final daquele ano lançar outros 14 números. Não se pode afirmar que essa promessa tenha se cumprido, pois não foi possível consultar os 12 números seguintes. No catálogo há apenas uma sinalização de que faltam tais números do periódico, e em outros locais não foi possível localizar até o momento.

Encontrei o periódico a partir do número 14, com data de 10 de dezembro de 1905, onde na primeira coluna afirmaram ter cumprido a empreitada de produzir todos os números prometidos. Nesse número foi feita uma homenagem ao representante da Santa Sé no Brasil, o Núncio Apostólico, com uma fotografia de D. Júlio Tonti no frontispício do último número daquele ano, como forma de agradecimento pela benção inicial e por todo incentivo.

5 Nos colégios jesuítas havia uma divisão relativa a idade dos alunos, os mais novos chamados "menores" e os mais velhos "maiores". 
Composto, na maioria das vezes, por quatro páginas "grandes", no formato de tablóide e impresso em folha jornal, tinha diagramação em três colunas, com tiragem de 300 a 500 cópias, e com valor variando entre $3 \$ 000$ e $4 \$$ ooo. Inicialmente foi impresso na Tipografia de $\mathrm{O}$ Friburguense, jornal local. Em 1911 passou a ter sua própria oficina tipográfica, como informou o periódico: "Nova Phase! Finalmente está dotada de oficinnas typographicas a Aurora Collegial, mimosa pupilla de nossos olhos" (Aurora Collegial, 19/7/1911, p. 1).

A oficina foi montada no porão, com 12 metros de largura por 9 metros de comprimento e 3 metros de altura. Neste amplo espaço foi instalada a máquina Nürnberg, de sistema cilíndrico, semi-rotativo, que pesava em todo conjunto 267 quilos. O tipógrafo era Palmerin Trannin, descendente de uma antiga família francesa, já experimentado no ofício.

Com a missão de aperfeiçoar e aumentar o conhecimento e o "fazer da pena”, com exceção deste primeiro número que trazia as notícias desde a páscoa, a proposta era de informar sobre os fatos mais notáveis da semana precedente. Com "leituras amenas", notícias do colégio e do exterior, e uma sessão recreativa, o periódico quinzenal, se declarava: "noticioso, instrutivo e recreativo, apropriado para jovens colegiais, consagrados ao estudo da língua pátria e da literatura que estes constituirão a maioria dos assinantes" (Aurora Collegial, 25/5/1905, p. 1).

O Aurora Collegial não tinha colunas fixas. As encontradas com mais recorrências foram as de abertura, que tratavam de homenagens ou aniversários dos padres, festividades religiosas, vidas de santos ou, ainda, notícias referentes ao Colégio. A "Chronica Collegial” era um texto dirigido ao leitor, no qual se relatava passeios, retiros, condolências, enfim, assuntos relativos à instituição. Já a partir de 1911, nota-se a presença de uma coluna que se tornou presente em todos os números, os "Trabalhos Collegiais”, que apresentava textos de alunos dos anos inferiores à Divisão dos Maiores, com temas variados, que na sua maioria apresentava uma lição de moral, aparentando ter passado pelo crivo de um padre ou um censor. Por fim, as "Risotas", que sempre finalizavam as páginas do periódico, davam um ar de descontração, pois traziam anedotas e “desa- 
fios” intelectuais, condizente com a juventude que escrevia naquelas páginas.

Na capa do primeiro número do jornal, a águia centralizada, os desenhos que a ladeiam, a imponente arquitetura do Colégio encravado nas serras da cidade de Nova Friburgo, sob a aurora, "o raiar do dia" ou "aquela que brilha como o ouro", parece anunciar o começo de um novo dia. No Brasil, Aurora é um nome predominantemente feminino e bastante comum, assim como a versão francesa Aurore. É um nome muito bonito e popular, devido a sua simplicidade e significado positivo e forte.

Figura 1 - Primeiro número do jornal Aurora Collegial (25/5/1905).

Fonte: Acervo do Colégio Anchieta.

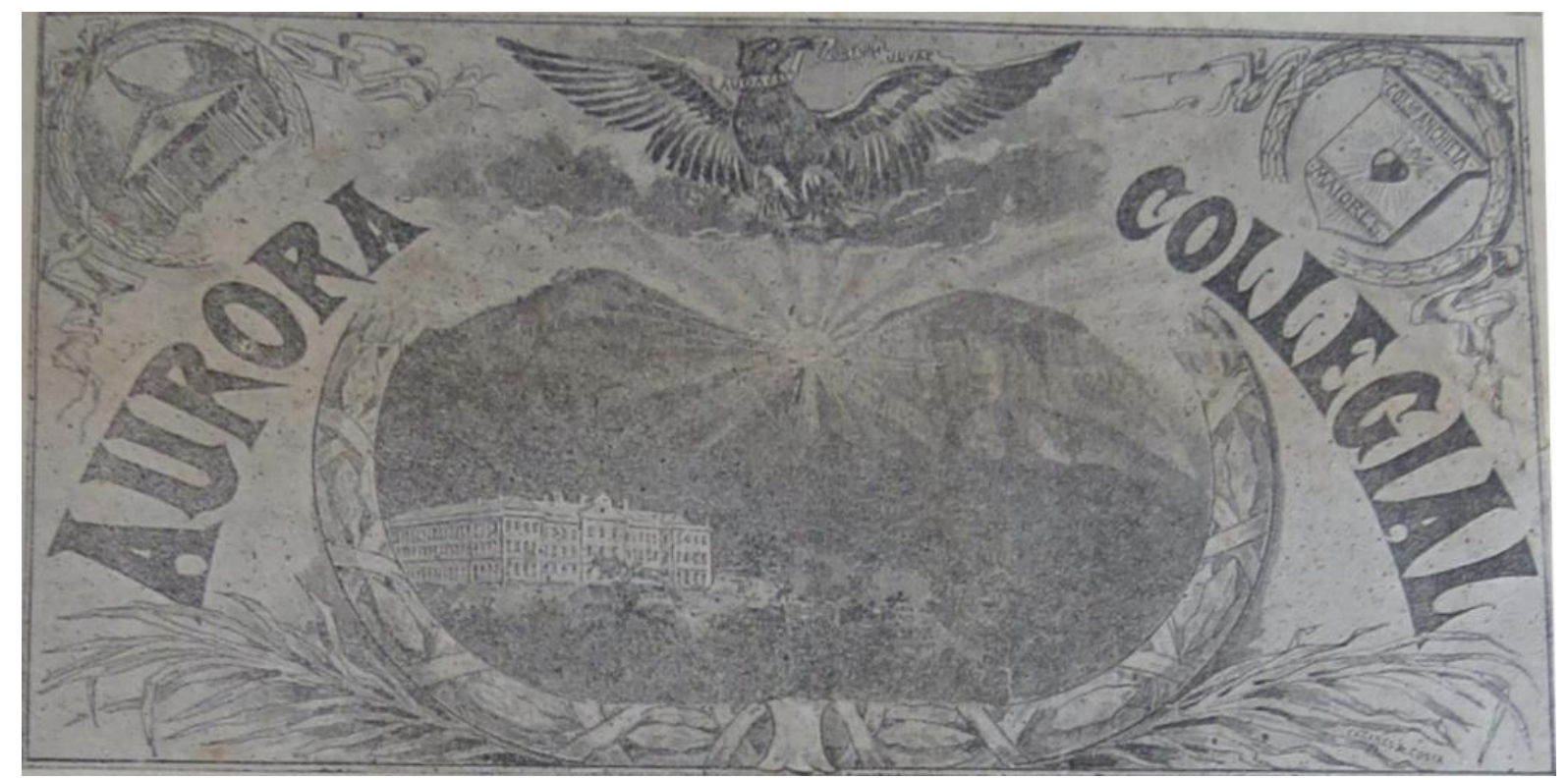

Observou-se que somente em seu primeiro número houve apenas três anúncios, localizados na última página, que se tratavam da Typographia O Friburguense e do Bazar Friburguense, dos irmãos Augusto e Américo Cardoso, que se justifica pelo fato da referida tipografia ser durante um bom tempo a responsável pela impressão do periódico. Outro anúncio, no final da página, era do padre autor de livros didáticos, Raphael Maria Galanti.

$\mathrm{O}$ anúncio de mais destaque foi dos livros do padre Galanti, enquanto os da Typographia Friburguense e do Bazar Friburguense divi- 
dem um pequeno espaço. Os manuais escolares escritos pelo padre jesuíta, por sua vez, tomam toda parte final da página. Suponho que esta diagramação foi uma forma de privilegiar as obras didáticas e em certa medida, abrilhantar seu professor.

Figura 2 - Anúncio no jornal Aurora Collegial.

Fonte: Acervo do Colégio Anchieta

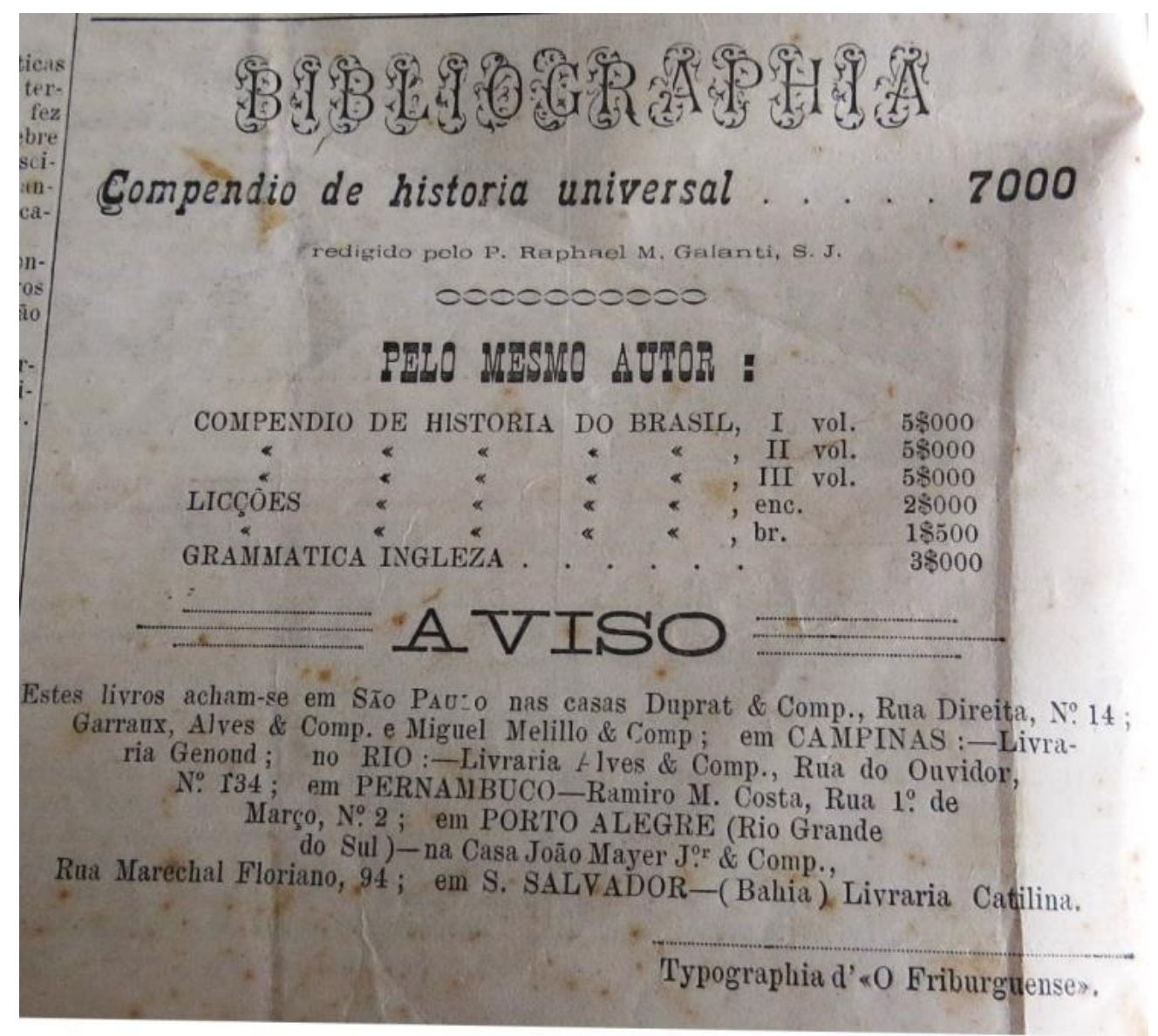

O jornal não tem muitas ilustrações, mesmo depois que passou a ter sua própria tipografia, salvo em homenagem ao Pontífice e ao Reitor, como nos números e fotos dos paraninfos, a partir de 1917. Nas folhas do periódico pode-se perceber, de certo modo, o cotidiano daquela instituição. O jornal deixa aparente sua sociabilidade e suas influências, por exemplo, quando seus autores destacam, em suas páginas, as correspondências recebidas e as "visitas" dos periódicos de outras instituições ou 
até mesmo jornais mais gerais, com circulação no estado do Rio de Janeiro.

A maioria das missivas transcritas pelo jornal era pedidos de alguns números que faltavam à coleção daquele leitor, como se pode notar no periódico do dia 14/7/1910, em que o senhor Alvaro Guião, do Colégio de Itu, em nome da redação do Collegio, jornal daquela instituição, se dirige ao secretário do Aurora.

\begin{abstract}
Acusando o recebimento da sua gentil cartinha, seja-me licito respondê-la, não só agradecendo a pronta remessa do "Aurora" como também participando, outrossim, que o entusiasmo para leitura da brilhante revista, cujos artigos, ataviados do mais puro vernaculismo rescendem triunfos literários, cresce dia a dia, pelo que pedimos mais cinco assinaturas (Aurora Collegial, 1910, p.2).
\end{abstract}

Há, também, a mensagem do padre jesuíta Alexandre Coutinho Castello, professor do Colégio Antônio Vieira, na Bahia, que além dos elogios proferidos, pede o aumento de mais duas assinaturas, perfazendo, assim vinte assinaturas. Pedidos e exaltações reproduzidos no periódico foram enviados ao Colégio Anchieta por postais e possibilitou indícios de onde circulava o jornal.

Outra forma de apreender a circulação e a influência que os autores do impresso possuíam, se dá pela nota, que não necessariamente compunha uma coluna, que se refere às "visitas" recebidas, como chamavam os impressos recebidos pelo colégio de Friburgo. No número de 7/9/1911, de forma mais alongada do que comumente, agradecem e descrevem brevemente cada um dos jornais e das revistas: $O$ Cruzeiro (Petrópolis), $O$ Collegio (Itu), O Gremio (Lorena), A Pátria Brasileira, O Albore Revista Social (Rio de Janeiro), O Ipiranga (Florianópolis), "Il Moadragone" (Colégio Romano), Ave Maria (São Paulo), Ora et Labora (Espanha), $O$ Arary, O Criterio, A Palavra (Pará), Imprensa da Matta (Minas Gerais), Trait d'Union (Bélgica), entre outros.

Parece que as "visitas" foram correspondidas, pois no final de muitas notas é possível encontrar a frase: "Retribuimo-lhes a visita!" (Aurora Collegial, 2/6/1911, p. 1). A partir daí depreende-se que o periódico da 
Divisão dos Maiores era enviado às redações dos jornais, revistas mencionadas e outros colégios da Companhia de Jesus. Aumentando a circulação dos seus conteúdos e suas propagandas.

Considerando o Aurora Collegial uma forma de dar-se a ver perante as instituições e outros jornais, as famílias e a sociedade em geral, pode-se apontar a relevância de difundir a vida social do colégio, visto que, em diversos números encontram-se passeios, comemorações e festividades. Também as sessões de cinema e a chegada da luz elétrica fazem parte do destaque feito pelos alunos. Como se pode observar no Diário Fluminense, a energia elétrica de baixa tensão foi para uso particular e público. Com a chegada da eletricidade começou o desenvolvimento da cidade, à medida em que, no final da década, deu-se o início de uma forte industrialização. ${ }^{6}$

O jornal menciona ainda as festas religiosas, como as do Sagrado Coração de Jesus, do Mês de Maria e de homenagem à Santo Inácio de Loyola, fundador da Companhia, com celebrações de missas com participação, inclusive, das famílias dos alunos. Passeios para fazendas próximas ou em outros estados eram realizados mensalmente por todos os alunos do colégio, com padres responsáveis e prontamente registrados nas páginas do jornal de modo à publicizar a rede de sociabilidade do educandário e o tipo de educação moderna que era oferecida.

No último número de 1911, o jornal teve oito páginas, o dobro do número habitual. No dia 31 de dezembro os colunistas narraram, naquele número, muitas comemorações. Na capa havia uma fotografia do Papa Pio X, a mesma que havia sido enviada pelo Vaticano para o colégio, com um honroso autógrafo, escrito originalmente em latim, mas traduzido para a "língua vernácula". Observava-se que muitos leitores do periódico talvez não dominassem a língua utilizada nos ritos da Igreja Católica, onde parabenizava e abençoava pelo $25^{\circ}$ aniversário de fundação do Colégio Anchieta. Por esta ocasião, houve uma comemoração de dois dias, realizadas em 9 e 10 de dezembro, com a presença do Cardeal do Rio de

\footnotetext{
${ }^{6}$ Conforme informação disponível na página do Centro de Documentação D. João VI: http://www.djoaovi.com.br/index.php?cmd=content:conto_a_inaugura\%E7\%E30_d a_luz_eletrica_em_nova_friburgo. Acesso em: 6 mai. 2017.
} 
Janeiro, Dom Joaquim Arcoverde, onde houve alvorada, realização de missa com banda e orquestra, fogos de artifício e iluminação da fachada do colégio.

Comemorou-se, ainda, o sétimo ano do Aurora Collegial, que foi lembrado por outros periódicos, como $O$ Universo, que destacou se tratar de um número especial "repleto de excellentes gravuras e escolhida colaboração da qual se deprehende o progresso sempre crescente desse notável estabelecimento de ensino" (Aurora Collegial, 1911, p. 5). O Friburguense, que durante seis anos foi responsável pela impressão do jornal, ressaltou a nitidez da fotografia e os artigos que narraram a história e os principais fatos do colégio.

A maior parte do impresso, porém, dedicou-se a "Solene Distribuição de Prêmios" realizada desde o início nos colégios jesuítas (cf. MENDONÇA, 2006; 2010), tratava-se do recebimento de medalhas pelos alunos e a menção de seus nomes nos Anuários do Colégio (relatório do ano letivo) e na imprensa local, ou do próprio colégio, por comportamento, aplicação nos estudos, progresso literário ou prévio concurso. A entrega de prêmios fazia parte do calendário festivo da instituição. Durante o evento se realizavam peças teatrais, apresentações de orquestra, configurando toda uma preparação para o ato maior: a entrega das medalhas que produzia a sensação de orgulho nos pais e de vitória para os alunos.

Estas atividades faziam parte do programa anual do colégio que "procuravam proporcionar educação estética impregnada de valores católicos" (DALLABRIDA, 2001, p. 178). Tais dramatizações fizeram parte das estratégias e táticas educacionais dos jesuítas para se apropriar da Ratio Studiorum, o método pedagógico dos jesuítas, que previa estas práticas com intuito educacional e religioso.

No dia 24 de maio de 1905 ocorreu no colégio um evento esportivo. O alpendre do palco, onde já se encontravam alguns padres, estava "ricamente enfeitado" com bandeirolas de cores variadas. "Abrilhantavam" o evento o padre Reitor, Galanti, Aurelli, Prosperi, Rubillon e Visconti. A premiação distribuída pelo Padre Reitor para os que tivessem mais "ligeireza já em pernas de pau, já em sacco ou pés amarrados, já com copos de água na mão, com ovo n'uma colher, ou no correr no pé coxinho" (Auro- 
ra Collegial, 1905, p. 2). Se por um lado essa gincana remete a um momento de descontração, as atividades físicas eram levadas a sério no colégio. Além desses exercícios, os rapazes jogavam futebol e tinham aulas de esgrima. A periodicidade das atividades físicas vai em direção à preocupação com a saúde e o desenvolvimento dos alunos. Ou, pelo menos, numa certa "prestação de contas" aos familiares, já que recebiam também eles eram leitores do jornal.

Foram lembradas pelo colunista com entusiasmo as sessões cinematográficas realizadas entre 15 e 17 de abril, cuja ressalva, de que naqueles dias não houve convidados eram apenas padres e alunos, ao todo foram assistidos oito filmes, a saber: "Fabricação de queijos", "Batalha de Legnano", "Tabella Marcada", "Os três irmãos", "Esqueleto recalcitrante", "A noite de natal da mestra”, "A boneca quebrada" e "O auxílio inesperado". Tratavam-se de filmes humorísticos, com lições de morais e históricas, com aproximadamente, duas horas de duração, apresentados no auditório do colégio, na qual a única reclamação foi: "não seria melhor e mais prático o haver programma explicativo das fitas, ou ao menos, quem de viva voz as explicasse e historiasse?" (Aurora Collegial, n. 85, p. 2). Essas sessões caracterizavam-se como mais uma via de instrução, ainda que o período não permitisse classificar como educativo. Mostrou também como o colégio já tinha um bom aparato material, aliando a educação, às novas tecnológicas e a modernidade.

Em maio de 1911, o sarampo e a influenza assolaram o colégio. Segundo a notícia, foram mais de 60 alunos acometidos pelas doenças, das três divisões, com apenas uma complicação, a do aluno da divisão dos médios, Mario Mello Palhares, que teve uma bronco-pneumonia. Esse aluno foi o único que partiu para sua casa e recebeu cuidados dos seus pais. Os demais se recuperaram no colégio, tratados pelo médico Galdino do Valle Filho e por irmãos jesuítas que eram enfermeiros, vindos do Colégio Santo Inácio, na capital do Rio de Janeiro. No número seguinte foi anunciado que o estado sanitário do colégio era bom. O prédio era amplo e com salões arejados, facilitando a convalescência, e estava localizado numa região com temperaturas amenas, que chegou ser refúgio de veranistas que saíam do Rio de Janeiro, principalmente no verão, devido aos 
altos índices de febre amarela, cólera, tuberculose que ceifou muitas famílias no final do século XIX (CORRÊA, 2009).

Possivelmente por isso, em novembro do mesmo ano, foi publicado um quadro comparativo do peso corporal de março e novembro, cujos alunos eram reconhecidos pelos seus números. Pode-se acompanhar no decorrer de nove meses considerável ganho de peso dos meninos e rapazes.

A partir de 1911, o jornal passou a ter uma coluna que nem sempre teve o mesmo nome, mas algumas vezes se chamou "Trabalhos Escolares”, onde eram publicadas produções de alunos. O jornal, que era de responsabilidade da divisão dos maiores, passou, então, a ter textos da divisão dos menores, do quarto e do quinto ano. São geralmente pequenos em extensão e referentes aos livros lidos, que traziam permanentemente uma lição de moral. Um destes, porém, chamou-me a atenção. Intitulado "Livros e cogumelos", do aluno do quinto ano Paulo A. Corrêa de Brito, que exclamou: "Que effeitos desastrosos não causam os máos livros!" (Aurora Collegial, 15/11/1911, p. 4). A partir de um diálogo entre dois meninos, supõe que um livro ruim fazia tão mal como um cogumelo, que envenena o corpo, pois o primeiro envenenava a alma. Eis a grande lição: não se deveria nem ao menos experimentar uma obra ruim, ainda que fosse com intuito de julgá-la.

Era uma crítica clara aos "maus livros". Ademais, deixa visível a intervenção que este periódico sofreu ao longo de suas publicações. Unindo-se a tal fato, destaca-se ainda um tom e um tratamento sempre muito formal para a escrita de meninos e rapazes, que além de possibilitar a forma de escrever vigente, fez notar o crivo do padre-redator, censor que revia textos e colunas, como acontece, com um ilustre aluno do Colégio Anchieta. Carlos Drummond de Andrade foi admitido em 1917 e expulso por "insubordinação mental" dois anos após seu ingresso. Mas, foi em 1979, neste trecho de "Fria Friburgo", que delata a censura:

...Já são quatro da tarde.

Até agora ninguém

veio gabar-me a nobre criação.

Ninguém gastou 300 réis para me ler? 
Será que meu escrito

não é lá uma peça tão sublime?

Decido-me a encará-lo mais a fundo.

Vou me ler a mim mesmo. Decepção.

O padre-redator introduziu

certas mimosas flores estilísticas

no meu jardim de verbos e adjetivos.

Aquilo não é meu. Antes assim,

ninguém me admirar. (ANDRADE, 2002).

Provavelmente, referindo-se a "Maio", uma das suas crônicas que abrem o jornal quinzenal, de 30 de abril de 1918. Saudando o mês de maio, mês mariano:

Raia o sol na alegria azul do céo; di-ser-ia que volta Primavera, entre harmonias orchestraes e toda terra reverdece, e se adorna de mimosas flores. Há rosas por todos os lados, rosas na terra, rosas no ar, rosas em tudo! (Aurora Collegial, n. 185, p. 1).

Este famoso aluno nunca mais retornou ao Colégio, nem mesmo ao ser convidado, como afirmou seu neto, dizendo que foi um ato tipicamente jesuíta. Nos anos 1980, no aniversário do colégio, ele foi convidado, mas recusou o convite: "Não vou voltar a um lugar do qual fui expulso"7.

O jornal Aurora Collegial prestou-se à instrução moral e cívica. Por meio da religiosidade, o impresso esteve sempre direcionando aos alunos e aos leitores em geral, que eram considerados "cidadãos dignos", por meio de leituras dos "bons livros", indicada pelos seus mestres.

Civicamente, encontrei nas suas páginas várias referências à Pátria. No jornal, em tom elogioso e transcrevendo o Jornal do Commercio, destacou o ex-aluno e segundo tenente da Marinha brasileira, Affonso Celso de Ouro Preto, por ter sido escolhido pelo Capitão de Mar e Guerra Campbell, que estudou com o Rei da Inglaterra, para uma vez por semana ministrar aulas de francês ao príncipe de Galles: “(...) deve agradar a todos brasileiros a notícia de que um seu jovem compatriota foi escolhido para preceptor do vindouro Rei da Inglaterra e Imperador das Índias” (Aurora Collegial, n. 95, p. 2). O elogio ao segundo tenente, em destaque

7 Conforme informação disponível em texto de Mauro Ventura publicado em $O$ Globo: http://oglobo.globo.com/cultura/o-despertar-de-carlos-drummond-de-andrade3730135. Acesso em: 6 mai. 2017. 
no Colégio, deu-se por ter recebido o título de bacharel daquela instituição, que emitia títulos de bacharel em Direito, Medicina, Politécnica e Escola Naval. Fora equiparado ao Gynasio Nacional Pedro II desde 1905, em regime que permaneceu por 10 anos.

A partir do ano de 1912 foi possível encontrar novas referências à pátria, desta vez, no formato de colunas ou mesmo páginas inteiras dedicadas à comemoração da independência do Brasil. Jonas Miranda, aluno

Figura 3 - Jornal Aurora Collegial.

Fonte: Acervo do Colégio Anchieta.

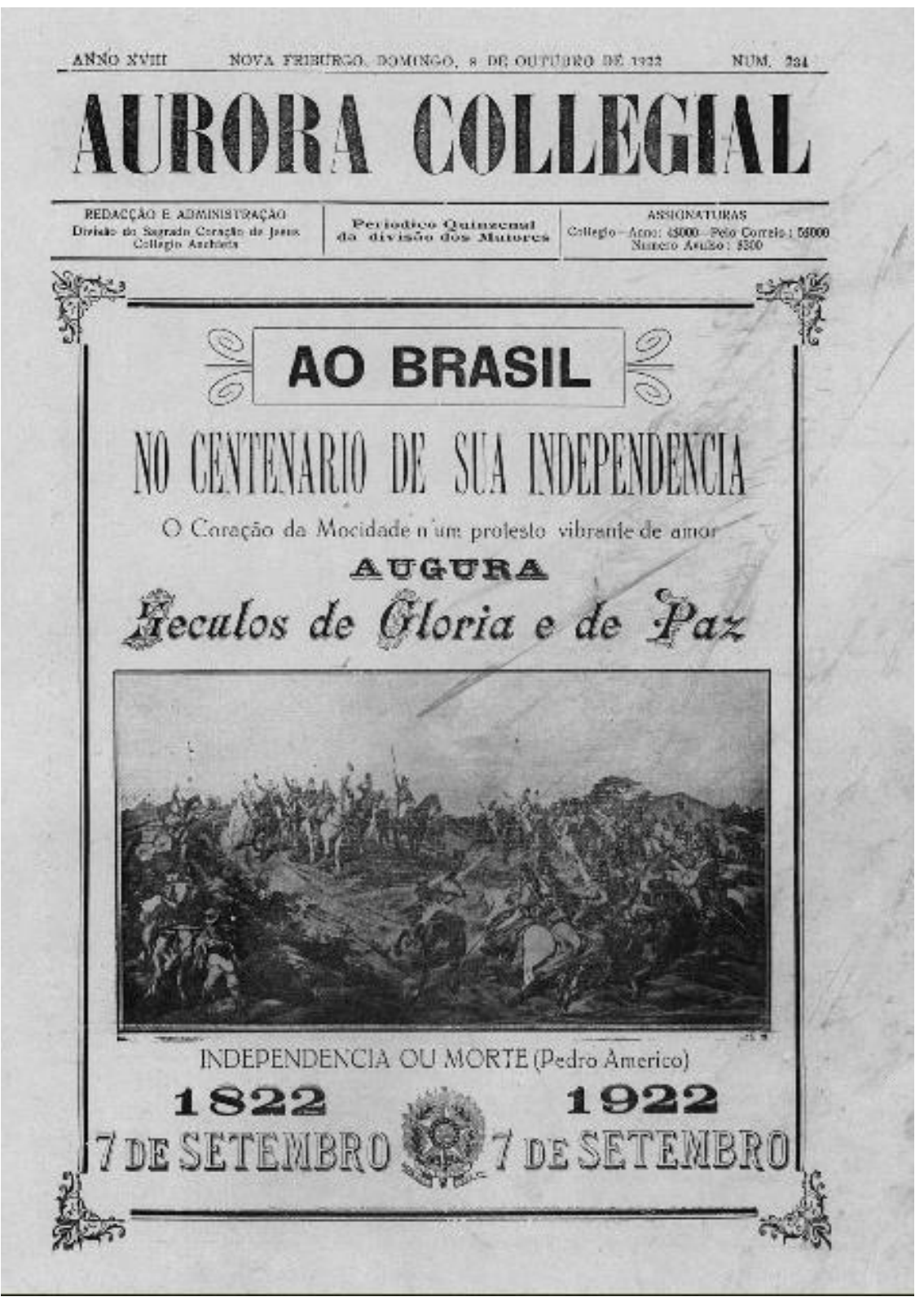

da Divisão dos Maiores, escreveu em 15 de setembro, sobre o patriotismo, desde os primeiros inacianos, com José de Anchieta e Manuel da Nóbrega, e que, em última instância se tratava de um sentimento, pois "não há progresso do pensamento nem do desenvolvimento do espírito que se não identifique à eterna verdade, no amplo seio do catholicismo" (Aurora Collegial, n. 111, p. 1). Em edição de 19 de setembro de 1915, conforme foi publicado na coluna intitulada "Sete de Setembro" foi 
comemorado o dia da liberdade da pátria, com a execução do hino nacional pela banda do colégio e uma sessão cinematográfica, sem indicar, porém, os filmes exibidos.

No ano seguinte, a publicação noticia outra festa cívica, em 17 de setembro. $\mathrm{O}$ evento, que ultrapassou os muros da instituição educacional, ocorreu na Praça XV de Novembro, com bandas e coros de outras instituições. A festa teve início às 5 horas da manhã, com 21 salvas de tiros. Ao meio dia, alunos de várias escolas se reuniram para ouvir discursos do prefeito da cidade, Dr. Mozart Lago, da diretora do Grupo Escolar Ribeiro de Almeida, Guaraciaba Leitão Thimoteo, e da professora Hercilia Bittencourt, com execuções dos hinos nacional e da independência, e distribuição de biscoitos para os alunos. E, por fim, houve o cortejo cívico pelas ruas, com mais de 1500 alunos. Às 6 horas houve o arreamento da bandeira nacional e finalizou com exibição de cinema ao ar livre. Esta comemoração, pela amplitude, parece ter envolvido boa parte da sociedade friburguense. Mereceu, inclusive, outro número do Aurora Collegial (n. 168, p. 2), em 2 de outubro, onde ainda se comentava sobre a festa: "certo permanecerá gravada em nossa mente por muitas primaveras e durante a nossa vida aqui, acho que não encontraremos outra igual”.

Por ocasião do centenário da Independência do Brasil, a edição de 8 de outubro de 1922 dedicou a capa e a primeira página inteira a esta comemoração. Num longo e exclamativo texto, Luiz H. Correia de Azevedo "refez" o caminho da história do Brasil até sua independência, com tom pujante de liberdade, exaltando que o povo brasileiro foi inteligente e realizou o que "o povo romano ousara predizer: 'felizes os povos que não tem história” (Aurora Collegial, n. 234, p. 2). O autor sugeriu ao longo da sua escrita o "apagamento" da história vivida antes da Independência, a que chama de vergonhosa, pois somente a partir daquele $7 \mathrm{de}$ setembro de 1822 que o Brasil se uniria às nações civilizadas.

O centenário da Independência foi comemorado com pompas, mostrando a civilidade do país, apesar do governo presidencial de Epitácio Pessoa, que este ano foi marcado por inúmeras instabilidades políticas e levantes militares. O Aurora Collegial buscou demonstrar em suas páginas a excelência da educação jesuíta católica, moral e científica, neste 
molde religioso e de civilidade, e teve a intenção de corroborar para a formação da mocidade.

\section{Considerações finais}

Assim, como desejou o Núncio Apostólico e o Conde Affonso Celso, em carta dirigida à redação do periódico, o jornal floresceu. Com mais de 15 anos de publicações quinzenais, cumpriu o papel a que se dispôs e foi noticioso, instrutivo e recreativo.

Mais do que desempenhar esta função, aqueles jovens alunos difundiram ideias e ideais, notícias e formas de escrever, mostrando aos seus leitores o que lhes era possivelmente relevante. A partir das notícias escritas no jornal, tornou-se possível apreender alguns significados daquelas práticas do colégio, e o que representavam para aquela rígida educação católica. O periódico testemunhou muitas dimensões, como a eloquência desejada, os temas debatidos e ressaltados e a ideologia corrente para Ordem Inaciana, seja, religiosa, política, moral e social.

A escrita do jornal com cunho moral e cívico fez referência à República e aos seus valores. Para uma elite brasileira, a qual esses jovens representaram os novos homens - aqueles a quem cumpria o papel de regenerar o país - o meio possível para realização desse projeto de nação foi a educação católica, moral e cívica.

\section{Referências}

ANDRADE, C. D. Poesia completa - conforme as disposições do autor. 1. ed. Rio de Janeiro: Nova Aguilar, 2002.

AQUINO, M. Modernidade republicana e diocesanização do catolicismo no Brasil: as relações entre Estado e Igreja na Primeira República (18891930). Revista Brasileira de História, v. 32, n.63, 2012. 
ARAÚJO, J. A. A. Arquitetura das residências das fazendas jesuíticas, no Estado do Rio de Janeiro, nos séculos XVII e XVIII: análise de um discurso espacial. Dissertação de mestrado (Ciência da Arte), Universidade Federal Fluminense, Niterói, 1999.

ARAUJO, J. R. Nova Friburgo: a construção do mito da Suíça brasileira (1910-1960). Tese de doutorado (História). Universidade Federal Fluminense, Niterói, 2003.

AZZI, R. Hierarquia, ordem e disciplina: os colégios de padres no Rio de Janeiro (1870-1920). Revista Rio de Janeiro, v. 1, n.1, p. 11-20, 1985.

BARROS, M. H. C. Amada pátria idolatrada: um estudo da obra Porque me ufano do meu país, de Affonso Celso (1900). Educar em Revista, n. 20, p. 245-260, 2002.

BENJAMIN, W. O narrador: considerações sobre a obra de Nikolai Leskov. Magia e técnica, arte e política: ensaios sobre literatura e história da cultura. São Paulo: Brasiliense, 1994, p. 197-221.

CASPARD, P. (dir.). La presse d'éducationet d'enseignement,. XVIIIe siècle-1940. Répertoire analytique. Paris: INRP. Tome 1: A-. C, 1981.

. Imprensa pedagógica e formação contínua de professores primários. In: CATANI, D.; BASTOS, M. H. C. (org.). Educação em revista: a imprensa periódica e a história da educação. São Paulo: Escrituras, 2002. CASTILLO GOMEZ, A. Historia de la cultura escrita: ideas para el debate. Revista Brasileira de História da Educação, v. 3, n. 1, 2003.

CATANI, D. B.; BASTOS, M. H. C. Educação em revista: a imprensa periódica e a história da educação. São Paulo: Escrituras, 1997.

CHARTIER, R. A história cultural: entre práticas e representações. Rio de Janeiro: Editora Bertrand Brasil, 1990.

. Práticas de leitura. $4^{\circ}$ ed. São Paulo: Estação Liberdade, 2009.

CHIOSSO, G. (dir.) La Stampa pedagógica e scolástica in Itália (18201943). Brescia: La Scuola, 1997.

CORRÊA, M. J. B. O cotidiano de Nova Friburgo no final século XIX: práticas e representações sociais. Rio de Janeiro: EDUCAM, 2008.

DALLABRIDA, N. A fabricação escolar das elites: o Ginásio Catarinense na Primeira República. Florianópolis: Cidade Futura, 2001.

DARNTON, R. O beijo de Lamourette. São Paulo: Companhia das Letras, 1990.

DE VROEDE, M. (dir). Bijdragen tot de geschiedenis van het pedagogisch leven in Belgie in de 19 de en 20 ste eeuw. De Periodieken, Gand Louvain, Rijksuniversiteitte Gent/Université Catholique de Louvain, 6 vol, 1973/1987.

HERNÁNDEZ DIAZ, J. M. Prensa pedagógica y património educativo em España: conceptualización y géneros textuales. In: Prensa pedagógica y 
património histórico educativo. Salamanca: Universidad de Salamanca, 2013, p. 15-32.

LUCA, T. R. História dos, nos, e por meio dos periódicos. In PINSKY, J. (org.). Fontes históricas. São Paulo: Contexto, 2005, p.111-153.

MENDONÇA, L. B. Educação Jesuítica: marcas do primeiro projeto educacional brasileiro. Rio de Janeiro, UNESA, 2006.

. O silêncio da ação: jesuítas no Brasil pós-Reforma Pombalina.

Rio de Janeiro, UERJ, 2010.

NÓVOA, A. Repertório da Imprensa de Educação e Ensino. In: A Educação Portuguesa. Corpus documental (séculos XIX-XX). CD-ROM, Porto: Edições ASA, 1993.

. A imprensa de educação e ensino: concepção e organização do repertório português. In: CATANI, D. B.; BASTOS, M. H. C. Educação em revista: a imprensa periódica e a história da educação. São Paulo: Escrituras, 2002, p. 11-31.

ROSA, L. R. de O. A Igreja Católica Apostólica Romana e o Estado Brasileiro: estratégias de inserção política da Santa Sé no Brasil entre 1920 e 1937, Franca: [s.n.], 2011.

SOBRINHO, J. A. B. Reminiscências dos primeiros tempos do Colégio Anchieta de Nova Friburgo. [s/d], 1955.

VIÑAO FRAGO, Antonio. Do espaço escolar e da escola como lugar: propostas e questões. In: FRAGO VIÑAO, A.; ESCOLANO BENITO, A. Currículo, espaço subjetividade: a arquitetura como programa. Rio de Janeiro: DP\&A, 1998, p. 59-139.

\section{Periódico}

AURORA COLLEGIAL. Colégio Anchieta, Nova Friburgo, Rio de Janeiro. 